\title{
A EDUCAÇÃO PARA O DESENVOLVIMENTO SUSTENTÁVEL NO CONTEXTO CURRICULAR DA REDE PÚBLICA DE ENSINO DO GOVERNO DO ESTADO DE SÃO PAULO: UMA BREVE REFLEXÃO PELA PERSPECTIVA DA DÉCADA DA EDUCAÇÃO PARA O DESENVOLVIMENTO SUSTENTÁVEL DA UNESCO (2005- 2014).
}

Eixo Temático (5): Política e Gestão Educativa - Educação para a Sustentabilidade.

Alexandre Marucci Bastos: Doutorando em Educação Escolar. UNESP - Universidade Estadual Paulista. Faculdade de Ciências e Letras. Pós-graduação em Educação. Rodovia Araraquara-Jaú, km 1 - Bairro dos Machados - Caixa Postal 174 - CEP: 14.800-901. Araraquara - SP - Brasil. E-mail: amarucci@ uol.com.br - fone: (16) 3308-1226.

Sebastião de Souza Lemes. Docente. UNESP - Universidade Estadual Paulista. Faculdade de Ciências e Letras - Departamento de Ciências da Educação. Rodovia Araraquara-Jaú, km 1 Bairro dos Machados - Caixa Postal 174 - CEP: 14.800-901. Araraquara - SP - Brasil. E-mail: ss.lemes2@gmail.com - fone: (16) 3334-6369.

RESUMO: A instituição da Década das Nações Unidas da Educação para o Desenvolvimento Sustentável (DNUEDS ou DEDS) foi aprovada em 20 de dezembro de 2002, na 57 Sessão da Assembleia Geral da ONU, ocasião em que se decidiu proclamar o período de dez anos - a partir de $1^{\circ}$ de Janeiro de 2005 até o final de 2014 - para que a educação fosse enfatizada como um elemento indispensável para alcançar o desenvolvimento sustentável. Nesse contexto, este estudo apresenta uma discussão sobre como tal proposição da ONU estaria sendo tratada pelas normas curriculares da rede pública de ensino gerenciada pelo Governo do Estado de São Paulo no último biênio da DEDS. Para tanto, desenvolveu-se uma análise das diretrizes curriculares delineadas pela respectiva Secretaria Estadual de Educação, verificando a que ponto as mesmas estariam alinhadas em relação aos propósitos da DEDS, sobretudo quanto à dinâmica curricular da rede pública escolar do governo paulista.

PALAVRAS-CHAVE: Década. Nações Unidas. Educação. Desenvolvimento Sustentável. Currículo.

\section{EDUCATION FOR SUSTAINABLE DEVELOPMENT IN THE CURRICULAR CONTEXT OF THE PUBLIC SCHOOL SYSTEM OF THE STATE OF SÃO PAULO: A BRIEF REFLECTION BY THE PERSPECTIVE OF UNITED NATIONS DECADE OF EDUCATION FOR SUSTAINABLE DEVELOPMENT - UNESCO (2005-2014).}

\begin{abstract}
The institution of the United Nations Decade of Education for Sustainable Development (UN DESD) was approved on December 20, 2002, at the 57th Session of the UN General Assembly, at which it was decided to proclaim the ten-year period - beginning on 1 January 2005 until the end of 2014 - so that education was emphasized as an indispensable element for achieving sustainable development. In this context, this paper presents a discussion of how such a proposition UN was being treated by the curricular standards of public schools managed by the State Government of São Paulo in the last two years of the DESD. For both developed an analysis of curriculum guidelines outlined by the respective State Education Department, verifying that the same point would be aligned in relation to the purposes of the DESD, especially regarding dynamic curriculum of the public school system of the state government.
\end{abstract}

KEY WORDS: Decade. United Nations. Education. Sustainable Development. Curriculum. 


\section{Introdução}

Tratar da Década das Nações Unidas da Educação para o Desenvolvimento Sustentável, sugere ao menos breves comentários preliminares sobre a própria expressão "desenvolvimento sustentável": a trajetória de sua concepção, seu posicionamento histórico, seu entendimento, sua essência e a extensão de sentido entre tal expressão e sustentabilidade.

Dessa forma, buscando contribuir com os estudos voltados para a compreensão dessa temática no âmbito das Ciências da Educação, o presente trabalho tem por objetivo apresentar uma discussão sobre como a proposição da ONU, representada pela Década das Nações Unidas da Educação para o Desenvolvimento Sustentável (DNUES ou DEDS: 2005-2014), estaria sendo tratada pelas normas curriculares da rede pública de ensino gerenciada pelo Governo do Estado de São Paulo, com ênfase no último biênio da DEDS.

Para tanto, desenvolveu-se uma análise das diretrizes curriculares delineadas pela Secretaria Estadual de Educação; verificando a que ponto as mesmas estariam alinhadas em relação aos propósitos da DEDS, sobretudo quanto a prevalecê-los na dinâmica curricular da rede pública escolar do governo paulista, na forma de uma necessidade real do cotidiano.

\section{O Desenvolvimento Sustentável e a Sustentabilidade}

De certa forma, a atual preocupação sobre os impactos ao meio ambiente provocados pelo homem teria sua gênese em decorrência da nova dinâmica na produção fabril instaurada com a Revolução Industrial, pela qual se ganhou escala industrial e propiciou maior acesso ao consumo generalizado em razão de redução de preços de produtos das mais diversas ordens. Se por um lado as indústrias consumiam mais insumos, combustíveis e matérias-primas, por outro a sociedade consumia mais os produtos industrializados, criando-se um ciclo que só fez aumentar resíduos sólidos, efluentes e poluentes (BASTOS \& SOUZA, 2013, p.208).

$\mathrm{O}$ acelerado ritmo de consumo de recursos naturais, junto à intensa e crescente produção de resíduos pela humanidade, chegou a tal ponto que as questões ambientais decorrentes desse cenário começaram a ser debatidas a partir dos anos de 1960, ganhando força na transição da década de 1960 para a de 1970, quando não havia mais como vilipendiar ou tergiversar essa questão. No ano de 1972, em destaque, foi publicado, em $1^{\circ}$ de março, pelo Clube de Roma, um estudo encomendado a um grupo de pesquisadores do Massachusetts Institute of Technology (MIT) sobre as tendências e os problemas econômicos que ameaçavam a sociedade global denominado Limites do Crescimento (THE CLUB OF ROME. Winterthur. Limits of Growth, 1972), trazendo então à luz da discussão o possível impacto do crescimento ilimitado no meio ambiente e ao próprio futuro da humanidade (THE CLUB OF ROME. Winterthur, 
[n.d.]). No mesmo ano de 1972, de 5 a 16 de junho, ocorreu a Conferência das Nações Unidas sobre o Meio Ambiente, em Estocolmo, na Suécia (ONU BRASIL, 1972).

O relatório do Clube de Roma e suas conclusões tiveram um impacto sem precedentes que marcou, em grande parte, a virada conceitual da década de 1970 e - ainda segundo o site oficial da organização ${ }^{1}$ - um notável giro copernicano do pensamento em termos ambientais, dando ainda, dentre tantas referências, o seguinte crédito ao documento:

Os efeitos internacionais desta publicação nas áreas de política, economia e ciência podem ser descritas como um "Big Bang": o Clube de Roma havia demonstrado a contradição do crescimento ilimitado e irrestrito do consumo de material em um mundo claramente finito de recursos e trouxe o tema para o topo da agenda global. (THE CLUB OF ROME. Capítulo Argentino [n.d.]).

Para Bastos e Souza (2013, p.211), na mesma essência do relatório do Clube de Roma mas não necessariamente como fato consectário -, na Conferência de Estocolmo abriu-se espaço para discutir e reavaliar o modelo de crescimento humano, sugerindo-se inclusive a criação de um Plano de Ação Mundial. Ensejo pelo qual foram debatidos temas relativos ao desenvolvimento, crescimento econômico e proteção ambiental. Tal Conferência acabou sendo um marco, e sua Declaração final representou um oportuno "Manifesto Ambiental".

Ao abordar a necessidade de inspirar e guiar os povos do mundo para a preservação e a melhoria do ambiente humano, o Manifesto proclamado em Estocolmo veio estabelecer as bases para a nova agenda ambiental do Sistema das Nações Unidas.

Chegamos a um ponto na História em que devemos moldar nossas ações em todo o mundo, com maior atenção para as consequências ambientais. A ignorância ou a indiferença podem causar danos maciços e irreversíveis ao meio ambiente, do qual nossas vidas e bem-estar dependem. Por outro lado, por meio do maior conhecimento e de ações mais sábias, podemos conquistar uma vida melhor para nós e para a posteridade, com um meio ambiente em sintonia com as necessidades e esperanças humanas...; Defender e melhorar o meio ambiente para as atuais e futuras gerações se tornou uma meta fundamental para a humanidade. (ONU Brasil, 1972).

Ainda na Conferência de Estocolmo foi deliberado, pelos governos presentes, que a ONU deveria criar um órgão encarregado de coordenar uma resposta global a esses desafios. Foi assim que, em dezembro de 1972, nascia o Programa das Nações Unidas para o Meio Ambiente - PNUMA (United Nations Environment Programme - UNEP), com sede em Nairóbi, no

1 THE CLUB OF ROME. Capítulo Argentino (n.d.). 
Quênia (UNEP, 1972). Segundo Bastos (2007, p.3), com o advento da Conferência de Estocolmo, em 1972, o debate sobre desenvolvimento ganhou a devida intensidade em escala global. Entretanto, ressalva o autor, não obstante o espectro de a discussão tratar de uma conjuntura mundial, principalmente por emular, contundentemente, as questões ecológicas e as de recursos não renováveis, o portal da conscientização sobre a importância de um desenvolvimento sustentável, além de franqueado, propiciou em decorrência que a altercação se expandisse além do âmbito econômico-ambiental.

Dessa forma, infere-se que tanto a publicação do Clube de Roma como a Conferência de Estocolmo não foram frutos do acaso. Elas resultaram das preocupações quanto ao crescente consumo da humanidade, sobre os riscos da degradação ambiental e a capacidade do planeta em suportar o ritmo do modelo econômico já, à época, estabelecido.

Eram criadas, assim, as bases para se conceber as expressões de desenvolvimento sustentável e sustentabilidade. Quanto à primeira, a própria UNESCO (2005, p.18) assevera que o conceito de desenvolvimento sustentável evolui constantemente; quanto à segunda

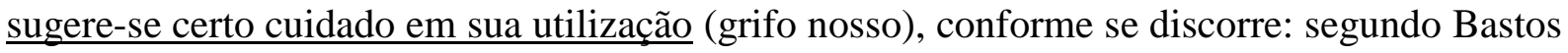
e Souza (2013, p.209), sustentabilidade refere-se à característica ou condição do que é sustentável; este, por sua vez, é aquilo que pode ser sustentado; passível de sustentação. Porém, os mesmos autores promovem uma ressalva ao destacar o fato de que, quando tais verbetes foram inseridos em uma abordagem sobre o tema desenvolvimento, houve tanto uma derivação como uma extensão de sentido, pelas quais o mundo despertou para uma nova realidade. Nesse contexto, destaca-se o entendimento à expressão proposto por Costanza, Daly e Bartholomew (1991). Embora reconheçam que o conceito de sustentabilidade requeira muita pesquisa adicional, os autores propõe a seguinte definição prática de sustentabilidade:

Sustentabilidade é uma relação entre sistemas econômicos humanos dinâmicos e sistemas ecológicos maiores igualmente dinâmicos embora normalmente mais lenta, em que (1) a vida humana pode continuar indefinidamente, (2) os seres humanos podem prosperar, e (3) as culturas humanas podem até se desenvolver; mas desde que sejam respeitados os limites de tais atividades humanas, de modo a não destruir a diversidade, complexidade e função dos sistemas ecológicos de suporte à vida. (tradução nossa, COSTANZA, DALY \& BARTHOLOMEW, 1991, p.8-9).

Pelo preconizado por Costanza, Daly e Bartholomew (1991, p.8-9) se constata a complexidade envolvendo o teor da expressão sustentabilidade, sobretudo quando os autores a coloca como um relacionamento entre sistemas econômicos dinâmicos e sistemas ecológicos maiores e também dinâmicos, embora de mudança mais lenta. Fato que exige atenção especial na sua utilização, bem como sua respectiva contextualização. Nesse contexto, pelas colocações 
de Bastos e Souza (2013, p.210), o atual entendimento sobre a terminologia sustentabilidade passou por várias contextualizações nas últimas décadas, compilando - em diacronia - outras expressões ao longo deste período. Segundo esses autores, surgiram, além das expressões sustentabilidade e desenvolvimento sustentável, conceitos como educação ambiental, ecodesenvolvimento, gestão ambiental, ecossistema, responsabilidade socioambiental, dentre outros; os quais ganharam, à sua maneira, em função de cada ensejo e conveniência, sua peculiar intensidade e respectiva importância.

Não obstante a suposta afinidade entre as expressões ecodesenvolvimento, desenvolvimento sustentável e sustentabilidade, Bastos (2007, p.29) ressalta que, ao contrário da terminologia ecodesenvolvimento, que sobreviveu por um curto período, o conceito de desenvolvimento sustentável, seu contemporâneo, teve mais ênfase em função de ter sido adotado em documentos importantes. Sua definição mais conhecida foi cunhada em 1987, pela Comissão Mundial sobre Meio Ambiente e Desenvolvimento (CMMAD), presidida pela então primeira-ministra da Noruega, Grö Harlem Brundtland, que adotou o conceito de desenvolvimento sustentável em seu relatório Nosso futuro comum (Our common future), também conhecido como Relatório Brundtland. Neste documento, foi definido que:

Desenvolvimento sustentável é o desenvolvimento que satisfaz as necessidades do presente sem comprometer a capacidade das gerações futuras satisfazerem suas próprias necessidades (Nosso futuro comum, UNITED NATIONS, 1987).

Souza (1994, p.7) destaca que muitos autores reconhecem que os avanços mais concretos em relação à formulação de uma teoria do desenvolvimento sustentável ocorreram a partir da divulgação do relatório Nosso futuro comum; já que esse documento ampliou as discussões sobre desenvolvimento e meio ambiente a partir do momento em que introduziu e interrelacionou uma significativa gama de parâmetros na formatação conceitual que configurou o desenvolvimento sustentável como uma nova estratégia de desenvolvimento.

O mesmo autor salienta ainda que, neste contexto, emergiram dois conceitos importantes da noção de desenvolvimento sustentável: o de desenvolvimento e o de sustentabilidade (grifos nossos), ambos caracterizados pela multiplicidade e controvérsia conceitual (p.11). Controvérsia conceitual essa, que se permite entender que ainda esteja imperando em viés nos dias atuais, conforme reconhece a ex-premiê norueguesa Brundtland, tida como a principal responsável por introduzir tais expressões no cotidiano mundial: 
Em entrevista concedida ao jornal Folha de S.Paulo ${ }^{2}$, publicada em 22 de março de 2012, Brundtland (2012, p.C17) assume que, para ela, a expressão é "desenvolvimento sustentável"; reiterando que esse é o conceito, apesar de, nos últimos anos, as pessoas adotarem a expressão "sustentabilidade" como uma forma alternativa de se referir ao teor do tema; alertando, ainda, que os conceitos de desenvolvimento sustentável e de sustentabilidade, têm sofrido abusos, especialmente das empresas.

A ex-premiê destaca o fato de ela sempre ter muito cuidado em não usar a palavra "sustentabilidade" isoladamente, tal qual um conceito que cobre a visão para o futuro; pois, para ela, o mundo precisa de sustentabilidade em diversas áreas, mas também precisa de desenvolvimento sustentável. Quando inquirida sobre o abuso e mau uso dos conceitos, como se houvesse um sequestro pelo mundo empresarial para fazer "greenwash" (no sentido de um apelo de marketing para dar aparência de verde), Brundtland (2012) faz a seguinte assertiva:

Acho que há mais abuso quando se fala de sustentabilidade. Porque essa palavra foi introduzida depois, num contexto diferente, como se entregasse aquilo que o desenvolvimento sustentável significa... Palavras sempre podem ser mal usadas. Mas não se pode simplesmente dizer: "Esse conceito foi distorcido, então deixamos o conceito de lado". Porque eu não acho que nós possamos encontrar uma maneira nova e melhor de descrever do que trataram a nossa comissão e a Rio92. Não vale a pena reinventar a roda porque alguém a roubou ou tentou roubá-la. Ela vai ser roubada de novo. Mesmo que alguém inventasse outra definição, e eu ainda não vi isso, eles encontrariam um jeito de fazer mal-uso dela. (BRUNDTLAND, 2012).

Mediante o exposto, percebe-se certo alerta quanto ao uso indiscriminado da expressão sustentabilidade, sobretudo quando tal utilização compromete a essência do que representa, de fato, um desenvolvimento sustentável. Nesse aspecto, ganha relevo a citação da "Rio-92" por Brundtland em sua assertiva. Tal evento, citado pela ex-premiê, refere-se à Conferência das Nações Unidas sobre o Meio Ambiente e o Desenvolvimento - CNUMAD (United Nations Conference on Environment and Development - UNCED) ${ }^{3}$, realizada na cidade do Rio de Janeiro, Brasil, de 3 a 14 de junho de 1992. Tal evento também é conhecido como o Grande Encontro da Terra ou Cúpula ou Cimeira da Terra; Eco 92 ou ainda Rio 92.

Portanto, nas palavras de Brundtland (2012) pode estar sublinhado o grande mérito do Encontro do Rio de Janeiro, de 1992: ter enrijecido a concepção conceitual do desenvolvimento sustentável. Sobretudo quando ela salienta que não houve ainda nova e melhor maneira de

BRUNDTLAND, 2012, p.C17.

In: BRASIL. Câmara dos Deputados. CNUMAD, 1995. 
descrever todo o significado de desenvolvimento sustentável, além daquelas já tratadas na Comissão que ela presidiu, em 1987, e a Rio-92.

Conforme colocam Bastos e Souza (2007, p.215), é neste ponto que ganha relevância os postulados de Ignacy Sachs (1993), pelos quais, deste a década de 1970, este autor já providenciava alguns dos fundamentos do debate contemporâneo sobre a necessidade de um novo paradigma de desenvolvimento, baseado na convergência entre economia, ecologia, antropologia cultural e ciência política. Dessa forma, Sachs (1993, p.24-27) aponta que, no processo de desenvolvimento, devem ser consideradas, simultaneamente, cinco dimensões de sustentabilidade, a saber: (1) ambiental; (2) econômica; (3) social; (4) cultural; e (5) espacial.

Se falar de sustentabilidade isoladamente já convoca uma abordagem criteriosa, inserir a educação ao contexto só tende a torná-lo mais complexo. Ou seja, colocar a educação (em sua forma mais ampla), a sustentabilidade e o desenvolvimento sustentável sob o mesmo enfoque, exige uma base teórica que suporte e compatibilize a lógica operacional pretendida. $\mathrm{O}$ que implicaria, em tese, priorizar a expressão Educação para o Desenvolvimento Sustentável em detrimento da expressão Educação para a Sustentabilidade, evitando-se dessa forma que não restasse certo vazio propositivo. Pela mesma abordagem criteriosa, deve-se posicionar o papel da Educação Ambiental nesse contexto, conforme pressupostos da ONU.

\section{A Educação conquistando seu espaço no debate preservacionista}

Apesar de não citar explicitamente a importância do papel da educação quanto ao futuro da humanidade à época de sua promulgação, em 1972, onde a Recomendação $n^{\circ} .96$ apenas coloca a Educação Ambiental como o elemento crítico para o combate à crise mundial, um trecho da Declaração de Estocolmo pode ser entendido como um indício correspondente: "Por outro lado, por meio do maior conhecimento e de açães mais sábias, podemos conquistar uma vida melhor para nós e para a posteridade, com um meio ambiente em sintonia com as necessidades e esperanças humanas" (grifos nossos, ONU BRASIL, 1972).

Todavia, se a questão ambiental, cuja importância estaria, segundo Bastos e Souza (2013, p.209), relacionada à própria sobrevivência do homem, envolvendo as necessidades primárias humanas - tais como a água para saciar a sede, o ar que se respira e até o alimento que nutre , esperou tanto tempo para receber a devida atenção mundial, resta em inferência paralela certa leitura de que a questão educacional, nesse sentido, aguardasse também seu momento ideal, de modo a favorecer os aspectos culturais e intelectuais ensejados. Uma abordagem histórica resumida que se traz à luz da discussão a seguir.

A despeito de obstáculos conjunturais das mais diversas ordens, Bastos e Souza (2013, p.209) destacam que, de certa forma, a perspectiva educacional a favor do meio ambiente 
chegou até mesmo anteceder o efetivo debate preservacionista em tela. Haja vista em 1965, durante a Conferência em Educação na Universidade de Keele, Grã-Bretanha, ter surgido o termo Educação Ambiental (Environmental Education) ${ }^{4}$.

Entretanto, para Bastos e Souza (p.209 e 222), ao longo de boa parte do horizonte de tempo subsequente, tal abordagem centrar-se-ia a princípio no campo da ação pedagógica voltada à conscientização, daí sua relevância e vigência de alcances internacionais residirem, até a década de 1990, no âmbito específico da Educação Ambiental, e não evocando, em tese, maior amplitude consoante à educação que contextualizasse de forma enfática o desenvolvimento sustentável. Todavia, esse cenário seria alterado a partir da Cúpula Mundial sobre Desenvolvimento Sustentável; realizada em Johanesburgo, na África do Sul, em 2002.

Nesse contexto, este estudo promove a seguir uma síntese em retrospectiva do trajeto cronológico que antecedeu o evento de Johanesburgo, em 2002. Síntese cronológica esta, onde são registrados os principais encontros globais relacionados com a questão ambiental, pelos quais o conceito de desenvolvimento sustentável foi sendo constituído e, sobretudo, como a educação foi sendo inserida, ao longo das décadas, ao debate preservacionista ${ }^{5}$ :

1965: Surge o termo Educação Ambiental - EA (Environmental Education) na Conferência em Educação, na Universidade de Keele, Grã-Bretanha.

1968: $\quad$ O Clube de Roma é fundado.

1971: Encontro Preparatório para a Conferência de Estocolmo, em Founex, Suíça.

1972: O Clube de Roma apresenta em $1^{\circ}$ de março, em Washington, nos Estados Unidos, o relatório Os Limites do Crescimento (Limits of Growth).

1972: $\quad 1^{\text {a } C o n f e r e ̂ n c i a ~ d a s ~ N a c ̧ o ̃ e s ~ U n i d a s ~ s o b r e ~ o ~ M e i o ~ A m b i e n t e ~ H u m a n o, ~ E s t o c o l m o, ~}$ Suécia (junho): desenha-se um plano de ação mundial para preservação e melhoria do ambiente. A Recomendação $n^{o} .96$ da Conferência reconheceu o desenvolvimento da Educação Ambiental (EA) como o elemento crítico para o combate à crise mundial. Nasce o PNUMA - Programa das Nações Unidas para o Meio Ambiente, sediado em Nairóbi, no Quênia.

1974: Simpósio da Comissão (Conferência) das Nações Unidas sobre Comércio e Desenvolvimento (UNCTAD) e do PNUMA, em Cocoyoc, México. Na Declaração de Cocoyoc surge nova percepção sobre a relação entre sociedade e natureza: existem limites ambientais e sociais para o desenvolvimento que devem ser respeitados.

1974: Seminário de Educação Ambiental (EA), em Jammi, Finlândia, estabelece os Princípios de Educação Ambiental: permite alcançar os objetivos de proteção ambiental, não sendo ramo da ciência ou matéria de estudos separada, mas ação integral permanente.

Conf. Bastos e Souza, 2013, p.221.

5 Síntese cronológica elaborada a partir de BASTOS (2007); MELLO e OJIMA (2004); GONZÁLEZ e GINDRI (2004); e MEDINA (1997). 
1975: Startup do Programa Internacional de Educação Ambiental (PIEA), Belgrado, Sérvia - antes Iugoslávia - ação alocada no Ensino Formal, com finalidade contínua, multidisciplinar, integrada às diferenças e voltada para os interesses nacionais.

1977: Declaração da Conferência Intergovernamental de Tbilisi, na Geórgia, sobre EA, organizada pela Organização das Nações Unidas para a Educação, a Ciência e a Cultura (UNESCO) em colaboração com o PNUMA.

1987: Congresso Internacional sobre a Educação e Formação Relativas ao Meio Ambiente, Moscou, Rússia, promovido pela UNESCO: edita a Estratégia Internacional de ação em matéria de educação e formação ambiental para o decênio de 90, que ressalta a necessidade de fortalecer as orientações de Tbilisi. A ênfase é colocada na formação de recursos humanos para a EA e na inclusão da dimensão ambiental nos currículos de todos os níveis de ensino:

A Educação Ambiental é um processo permanente no qual os indivíduos e as comunidades adquirem consciência do seu meio e aprendem os conhecimentos, os valores, as habilidades, a experiência e também a determinação que lhes capacite agir, individual e coletivamente, na resolução dos problemas ambientais presentes e futuros (IBRAM-DF, 2001).

1990: A Conferência Mundial sobre Educação para Todos (World Conference on Education for All - WCEFA), Jomtien, Tailândia, aprova o plano de ação para satisfazer as necessidades básicas de aprendizagem. O evento foi patrocinado pela UNESCO, pelo Fundo das Nações Unidas para a Infância (United Nations Children's Fund-UNICEF) e pelo Programa das Nações Unidas para o Desenvolvimento - PNUD.

1992: Grande Encontro da Terra. Conferência das Nações Unidas sobre o Meio Ambiente e o Desenvolvimento, CNUMAD-92. Rio-92 (ou Eco-92): Agenda 21.

2000: A Conferência Regional de Educação para Todos nas Américas, em Santo Domingo, República Dominicana, que definiu o Marco Regional de Ação de Santo Domingo e o Fórum Mundial sobre Educação, em Dakar, Senegal, África, que instituiu a Educação para Todos: $O$ compromisso de Dakar. Ambos os documentos permitem uma abordagem da educação para o desenvolvimento sustentável.

\section{A Educação para o Desenvolvimento Sustentável e sua Década definida pela ONU}

Conforme se constata pela síntese cronológica da seção anterior, até o início da década de 1990, as questões educacionais relacionadas à perspectiva preservacionista estavam sob a influência do enfoque no campo da ação pedagógica voltada à conscientização propiciada pela Educação Ambiental, pela qual chegou a se enfatizar a formação de recursos humanos e a inclusão da dimensão ambiental nos currículos de todos os níveis de ensino.

No entanto, tal dinâmica, envolvendo os aspectos culturais e intelectuais, iniciou um processo de significativas alterações a partir do Grande Encontro da Terra, a Conferência das Nações Unidas sobre o Meio Ambiente e o Desenvolvimento, CNUMAD-92. (Rio-92 ou Eco- 
92). Conforme registram Souza (1994) e Arid (2003), o Encontro de 1992, além de aprovar o Relatório Brundtland, promulgou cinco documentos principais: Agenda 21 (BRASIL. MMA, [n.d. a e b]); Declaração do Rio de Janeiro sobre o Meio Ambiente; Declaração de Princípios sobre o Manejo Florestal; Convenção sobre Diversidade Biológica; e Convenção Geral sobre Alterações Climáticas. Os países signatários comprometeram-se a cumprir os programas e a considerar a degradação ambiental como causa da pobreza, da fome e da ignorância.

Para SACHS (1993, p.59), dos cinco documentos principais resultantes da Eco-92, a Agenda 21 pode ser considerada como o mais importante e de maior alcance, mesmo ela sendo configurada como um programa de ação em forma de recomendações, revestido pelo caráter da não obrigatoriedade. A despeito de certo ceticismo que incidiu sobre a Agenda 21 (por ser facultativa), ela foi "sancionada" pela comunidade internacional, propiciando um novo e vigoroso impulso ao desenvolvimento socioeconômico; o qual é condição sine qua non de uma estratégia planetária comum para a gestão do meio ambiente e dos recursos, capaz de deter, ou pelo menos reduzir e adiar, os efeitos deletérios da mudança global (p.60).

Os temas fundamentais da Agenda 21 foram tratados em 40 capítulos organizados em quatro Seções, compreendendo 1.412 parágrafos, distribuídos por 118 áreas de programas, conforme o tema de cada capítulo (BRASIL. CNUMAD, 1995). Nesta estrutura - e não obstante a educação ser considerada em vários contextos da Agenda 21 -, pode-se dizer que os aspectos educacionais foram tratados com mais ênfase - e especificidade - na Seção IV do documento: Meios de Implementação, sobretudo no Capítulo 36: Promoção do ensino, da conscientização e do treinamento, pelo qual a educação ambiental passou a fazer parte de um todo, representando pelo ensino no contex to programático.

O referido capítulo preocupou-se em promover a fusão dos princípios fundamentais contidos na Declaração - e nas recomendações - da Conferência de Tbilisi (de 1977), sobre Educação Ambiental, com as recomendações da Conferência Mundial de Jomtien (de 1990), pelas quais foi dada maior amplitude à educação no debate. Nesse propósito, o Capítulo 36 compreendeu três áreas de programas, a saber: (a) Reorientação do ensino no sentido do desenvolvimento sustentável (grifo nosso); (b) Aumento da consciência pública; e (c) Promoção do treinamento. Cada uma destas áreas tendo sua respectiva base de ação.

Para assegurar o total apoio aos objetivos da Agenda 21, a Assembleia Geral da ONU estabeleceu a criação de uma comissão específica para monitorar a implementação dos acordos da Cúpula da Terra. Dessa forma, da Conferência Rio-92 resultou na criação, em 1993, dentro do sistema das Nações Unidas, da Comissão de Desenvolvimento Sustentável (CDS) como uma comissão funcional do Conselho Econômico e Social (ONU BRASIL, n.d.). 
Foi assim que a Assembleia Geral das Nações Unidas, sustentada pelos propósitos da CDS, realizou uma sessão especial ${ }^{6}$ em 1997, chamada de "Cúpula da Terra +5" (+5 em alusão aos cinco anos decorridos do Encontro do Rio de Janeiro: Rio+5). Tal evento, na verdade, buscou consolidar em um só documento, recomendações para equalizar as dificuldades de implantação detectadas em diversos encontros antecedentes naquele ano de 1997. Pode-se dizer que da Cúpula Rio+5 restou apenas o relato oficial das dificuldades em avançar de uma retórica propositiva da Agenda 21 para ações mais efetivas.

Se a Rio+5 não proporcionou avanço pragmático significativo, sobretudo quanto à educação no desenvolvimento sustentável, o mesmo não se pode dizer da Cúpula Mundial sobre Desenvolvimento Sustentável; realizada em Johanesburgo, na África do Sul, entre 8 de agosto e 4 de setembro de 2002, para novamente fazer um balanço das conquistas, desafios e das novas questões surgidas desde a Conferência Rio-92, daí sendo denominada de Rio+10.

Apesar de algumas publicações colocarem a Rio+10 como um evento de pouco pragmatismo $^{7}$ - semelhante ou até mesmo em um patamar de intensidade inferior ao da Conferência Rio+5 -, quando o foco da leitura é direcionado para as questões educacionais, constata-se que o Encontro de Johanesburgo assentou uma pedra fundamental: quando dela se obteve um importante documento relacionado à educação: a Declaração de Johanesburgo sobre Desenvolvimento Sustentável, vindo a estabelecer o Plano de Implementação da Cúpula Mundial sobre Desenvolvimento Sustentável ("Plano de Implementação de Johanesburgo"), pelo qual se confirmou a importância da educação para o desenvolvimento sustentável (grifo nosso) e recomendou que a Assembleia Geral das Nações Unidas considerasse a adoção de uma década de educação para o desenvolvimento sustentável a partir de 2005, a DEDS.

\section{A DEDS (DNUEDS) 2005-2014 e a EDS}

Em relação à DEDS, a Rio+10 poderia ser considerada um marco, pois a recomendação de Johanesburgo foi acatada poucos meses depois de sua proposição, quando, em 20 de dezembro de 2002, na 57ª Sessão da Assembleia Geral das Nações Unidas, a Resolução 57/254 (UNITED NATIONS, 2002) foi aprovada; pela qual a educação foi enfatizada como um elemento indispensável para alcançar o desenvolvimento sustentável, decidindo proclamar o período de dez anos, a partir de $1^{\circ}$ de Janeiro de 2005, como a Década das Nações Unidas da Educação para o Desenvolvimento Sustentável: DNUEDS 2005-2014.

6 Sessão Especial da Assembleia Geral para o Exame e Avaliação da Implementação da Agenda 21. Nova York, EUA, dos dias 23 a 27 de junho de 1997.

7 Nesse sentido, considerar o ânimo mundial que possa ter influído a Rio+10: realizada às vésperas do $1^{\circ}$ ano do ataque às torres do World Trade Center (Nova York), em 11/9/2001. 
Para chancelar a oficialização da DEDS, na 59ª sessão da Assembleia Geral das Nações Unidas (Nova York, nos dias 18 e 19 de outubro de 2004), foi apresentado o Plano Internacional de Implementação da United Nations Decade of Education for Sustainable Development 2005 2014 - Draft International Implementation Scheme. No Brasil, tal documento gerou o Plano Internacional de Implementação da Década da Educação das Nações Unidas para o Desenvolvimento Sustentável: documento final do esquema internacional de implementação; publicado, em maio de 2005, pelo escritório brasileiro da UNESCO, em Brasília-DF (UNESCO, 2005).

A Década da Educação para o Desenvolvimento Sustentável - DEDS -, assim denominada na publicação brasileira, é, segundo a UNESCO (2005, p.16), uma iniciativa ambiciosa e complexa. Seus fundamentos conceituais, repercussões socioeconômicas e incidência no meio ambiente e na cultura afetam todos os aspectos da vida. O objetivo global da DEDS é integrar os valores inerentes ao desenvolvimento sustentável em todos os aspectos da aprendizagem com o intuito de fomentar mudanças de comportamento que permitam criar uma sociedade sustentável e mais justa para todos.

Nesse sentido, embora reconheça que a DEDS possua em sua essência uma ideia simples, a UNESCO adverte sobre sua complexidade, sobretudo quando se coloca o desafio de estimular mudanças de atitudes e comportamento na sociedade mundial, consoantes à necessidade de aprender a viver de forma sustentável. O que exige compatibilizar nossas capacidades intelectuais, morais e culturais frente às responsabilidades impostas para com todos os seres vivos e para com a natureza como um todo (UNESCO, 2005, p.9).

Para enfrentar tal desafio, foi criado o programa Educação para o Desenvolvimento Sustentável - EDS, pelo qual é enfatizado o papel central da educação na busca comum pelo desenvolvimento sustentável, tendo ela a função de prover os valores, atitudes, capacidades e comportamentos essenciais para confrontar esse cenário desafiante (UNESCO, 2005, p.10). O documento, em si, pretendeu estabelecer que a EDS fosse uma realidade concreta para todos nós - indivíduos, organizações, governos - em todas as nossas decisões diárias e ações, de modo a deixarmos como legado um planeta sustentável e um mundo mais seguro, sendo que a implementação da DEDS iria depender do nível de comprometimento dos interessados e de cooperação dos níveis local, regional, nacional e internacional (idem, p.21).

\section{A essência dos propósitos da EDS como subsídios a uma proposta curricular}


Considerando certo caráter crepuscular, já que oficialmente a DEDS se encerra neste ano de 2014, a conotação pretérita se fez sobremodo recorrente na redação desta seção.

Conforme é enaltecido pela UNESCO (2005, p.18), o programa Educação para o Desenvolvimento Sustentável (EDS) trata fundamentalmente de valores, nos quais o respeito seria o tema central: respeito ao próximo, incluindo às gerações presentes e futuras, à diferença e à diversidade, ao meio ambiente e aos recursos existentes no planeta que habitamos. No entanto, a própria UNESCO reconhece o desafio que consistiria em estimular mudanças de atitudes e comportamento na sociedade mundial, o que exigiria compatibilizar nossas capacidades intelectuais, morais e culturais nesse sentido (p.9).

Em função do respeito mútuo evocado, caberia uma leitura pela qual cada indivíduo seria parte interessada na EDS, onde cada um sentiria as consequências do seu êxito ou de seu fracasso, inclusive influenciando seu respectivo programa decorrente de comportamentos coletivos, quer sejam favoráveis ou desfavoráveis (UNESCO, 2005, p.20). Talvez por isso, a DEDS vaticinou que o êxito da EDS estaria atrelado ao devido esclarecimento do significado e do objetivo do desenvolvimento sustentável, sobretudo pelo fato de este conceito evoluir constantemente. Para tanto, o programa EDS apresentou três áreas principais de abordagens: sociedade, meio ambiente e economia, tendo a cultura como dimensão de base (p.18).

Valores, diversidade, conhecimento, linguagens e visão mundial, associados à cultura, influenciam fortemente o modo de abordar os distintos aspectos da educação para o desenvolvimento sustentável em cada delimitação geográfica. Neste sentido, cultura não se limitaria apenas a uma série de manifestações específicas (música, dança, vestuário, culinária, por exemplos), mas a uma maneira de ser, de se relacionar, de se comportar, de acreditar e agir durante toda a vida, e que está em constante evolução. Quanto à sociedade, esta compreenderia o conhecimento das instituições sociais e do papel que desempenhariam na mudança e no desenvolvimento social, assim como dos sistemas democráticos e participativos, que dariam oportunidade de expressar opiniões, eleger governos, estabelecer consensos e resolver controvérsias (UNESCO, 2005, p.18).

Por meio do conhecimento e, consectário, do estímulo em mudar comportamentos e atitudes, haveria melhores condições para a sociedade ter a devida consciência em relação aos recursos e à fragilidade do meio ambiente físico e aos efeitos das atividades e decisões humanas relativas ao meio ambiente como um todo. Na mesma linha de conscientização, a abordagem econômica definiria os respectivos limites consoantes ao potencial do desenvolvimento econômico, bem como de seus impactos na sociedade e no meio ambiente, com o compromisso 
de colocar em níveis adequados o consumo individual e coletivo, levando em consideração os aspectos ambientais e a justiça social.

Mediante o exposto, é possível perceber a intensidade dos desafios que seriam enfrentados pela EDS, entre os quais se acrescentaria o de diferenciar-se da Educação Ambiental, distinção essa, que o próprio documento da DEDS buscou estabelecer:

A educação para o desenvolvimento sustentável não deve ser equiparada à educação ambiental. Educação ambiental é uma disciplina bem estabelecida, que enfatiza a relação dos homens com o ambiente natural, as formas de conservá-lo, preservá-lo e de administrar seus recursos adequadamente. Portanto, desenvolvimento sustentável engloba educação ambiental (grifo nosso), colocando-a no contexto mais amplo dos fatores socioculturais e questões sociopolíticas de igualdade, pobreza, democracia e qualidade de vida. A perspectiva de desenvolvimento - envolvendo mudança social e evolução das condições - é também central para qualquer análise do desenvolvimento sustentável. O conjunto de objetivos de aprendizagem do desenvolvimento sustentável é, portanto, de largo alcance. Desenvolvimento sustentável deve ser integrado em outras disciplinas e não pode, em função do seu alcance, ser ensinado como uma disciplina independente. (UNESCO, 2005, p.46).

Destarte, pelo teor do documento final do esquema de implementação elaborado pela UNESCO (2005), é possível elencar alguns pontos cruciais em relação à DEDS e à EDS:

- A paz, a saúde e a democracia são consideradas como pré-requisitos do desenvolvimento sustentável que se reforçam mutuamente.

- A educação é fundamental para promover o desenvolvimento sustentável e melhorar a capacidade das pessoas em entender os problemas do desenvolvimento e do meio ambiente, sendo ela a força motriz para que ocorra qualquer mudança necessária.

- A EDS, em função de sua abrangência multidimensional, não deve ser equiparada à Educação Ambiental. Um contexto que, inclusive, faria a EDS englobar a EA.

- Pelo fato de o processo ser essencialmente revestido pelo manto democrático, caberia à própria sociedade decidir se a EDS consistiria em uma necessidade real do cotidiano.

Ainda segundo os pressupostos do mencionado documento final (UNESCO, 2005, p.20), a EDS deveria ser aplicada a todas as pessoas, independentemente de idade. Ela ocorreria, dessa forma, em meio a uma perspectiva de aprendizado ao longo da vida, envolvendo todos os espaços de aprendizagem possíveis - formal; não formal e informal -, desde a primeira infância até a idade adulta. EDS, assim, requeria a reorientação das abordagens educacionais - currículo e conteúdo, pedagogia e avaliações. Nesse contexto, a EDS deveria ser considerada como uma 
linha propositiva que serviria de guia ao longo do percurso a ser percorrido pelos alunos durante todo o sistema educacional - da pré-escola até a educação superior - algo que, em tese, iria maximizar a capacidade de conscientização dos discentes sobre a essência de um desenvolvimento sustentável (p.61).

Seguindo pela mesma linha propositiva, o programa EDS salientou sobre o quanto seria peremptório que a política educacional fosse reexaminada, no sentido de reorientar o percurso propedêutico, inclusive provendo condições para um aprendizado permanente na vida adulta, de modo a perpetuar, em cada cidadão adulto, a aquisição contínua de conhecimentos, competências, perspectivas e valores relacionados ao que seria de fato um mundo sustentável. Para isso, seria necessário revisar pro ativamente os objetivos e conteúdo dos currículos para promover uma compreensão interdisciplinar envolvendo as dimensões da sustentabilidade ${ }^{8}$ : social, econômica, ambiental, espacial e cultural (UNESCO, 2005, p.57).

Concomitantemente aos aspectos curriculares, os sistemas educacionais precisariam de reformulação para que este tipo de aprendizagem fosse validado por meio de uma avaliação sistematizada; e que a formação dos docentes os preparasse para processos de aprendizagem ativos/interativos, em vez de mera transferência unilateral de conhecimento. Ademais, no caso de esse tipo de aprendizagem ser distribuído de maneira desigual para toda a população, todo o processo poderia ser enfraquecido, comprometido. Dessa forma, o conteúdo específico dos currículos deveria ser construído de uma maneira ampla, tomando como referência o contexto local, considerando questões de relevância e de urgência (UNESCO, 2005, p.57)

Quando de seu lançamento, a EDS trazia consigo a pretensão de refletir a preocupação por uma educação de alta qualidade, devendo ser interdisciplinar e holística, de modo a priorizar um aprendizado voltado para o desenvolvimento sustentável como parte integrante do currículo como um todo, não como disciplina ou matéria à parte (p.18 e 46).

Entretanto, para que a EDS tivesse um futuro duradouro, tanto a sociedade como os atores do universo educacional deveriam estar convencidos da sua real necessidade (grifo nosso), principalmente os professores, os quais, inclusive, precisariam dispor de métodos para integrar a EDS nas suas práticas docentes, algo que implicaria na própria capacitação de professores nesse sentido (p.61). Os currículos, por sua vez, precisariam ser desenvolvidos incluindo conteúdo, materiais e ferramentas, assim como estudos de casos e identificação das melhores práticas em relação à essência de um desenvolvimento sustentável (p.63).

\footnotetext{
8 Apesar de Sachs não ser citado ao longo do documento elaborado pela UNESCO (2005) para a implementação da DEDS e da EDS, essa abordagem, especificamente, converge aos postulados multidimensionais desse autor, já colocados à luz da discussão neste texto (SACHS, 1993, p.24-27).
} 
Segundo a UNESCO (2005, p.79), a EDS não seria um programa independente, mas se integraria em uma gama de situações diferentes de aprendizagem. Nesse aspecto, em que pese o fato de uma contundente transversalidade, ajudaria em muito delinear hipóteses sobre as características que deveriam reunir uma EDS de alta qualidade, como por exemplo: em diferentes tipos de escolas, em círculos de educação de adultos, na extensão dos programas de desenvolvimento, em distintos contextos geográficos e socioculturais, na estrutura de diferentes disciplinas que cada hipótese deveria incluir e de acordo com a situação a que ele se dirige. Para tanto, haveria de se atentar a alguns pontos, entre os quais: meios de detectar os principais problemas locais em matéria de desenvolvimento sustentável; possíveis estratégias de aprendizagem; modalidades de integração do saber com a cultura local; e processos democráticos de elaboração de currículo escolar que permitiriam decidir localmente os conteúdos programáticos considerando os princípios do desenvolvimento sustentável (idem)

"Dinâmica democrática" e "necessidade real do cotidiano". Expressões chaves que por certo afetariam eventuais discussões sobre currículo. Nesse sentido, partindo do princípio de que a operacionalidade da educação tem na escola uma de suas principais formas de materialização, ganha relevância uma abordagem democrático-escolar. Para Lemes (2013, p.170), a escola democratizada, no momento, é algo ainda a se alcançar no Brasil, apesar de já se ter muito a defender. Pois uma escola efetivamente democrática em terras tupiniquins ainda estaria em construção, ou seja, embora estabelecida por marco legal, ainda não a temos, de fato, no cotidiano de nossas instituições.

Com base na contextualização procedida por Lemes (2013), em uma escola democratizada, portanto, é preciso que se compreenda a necessária flexibilidade da organização curricular, de forma que tal procedimento seja adequado aos desafios que serão postos para essa trajetória na sua complexidade e circunstancialidade (p.170), algo que o documento de implementação da DEDS-EDS levou em consideração. Contudo, as dificuldades que se apresentariam para o currículo, em uma escola democratizada, vêm se ampliando por entraves vindos de políticas públicas que precisam atender demandas de realidades tão diferentes quanto complexas (p.177), tal qual se faz a EDS nesse sentido.

Além dos aspectos curriculares, há a questão temporal a eles relacionada. Pelo ínterim decenal da DEDS - e a plurianualidade imposta pela assunção da EDS como linha guia ao longo de um percurso propedêutico ilimitado - seriam gerados ciclos de aprendizagem ao longo de 
vários anos. Nesse contexto, Perrenoud (2004, p.14) enumera e discute com propriedade algumas razões para que se empreguem os ciclos plurianuais de aprendizagem, os quais sugerem plausível pertinência quanto aos propósitos da DEDS e da EDS.

Dentre as razões elencadas por Perrenoud (idem) para justificar os ciclos plurianuais, há pontos que abrangem desde a definição de etapas mais compatíveis em relação à progressão de aprendizagem, até a questão de um planejamento flexível de tais progressões, sobretudo quanto ao atendimento diferenciado em função da diversidade de públicos-alvo discentes. No entanto, duas outras razões são aqui destacadas, as quais estariam diretamente relacionadas com o pretenso êxito da DEDS e da EDS: (1) uma maior continuidade e coerência, ao longo de vários anos, sob a responsabilidade de uma equipe; e (2) objetivos de aprendizagem incidindo sobre vários anos, constituindo pontos de referência essenciais para todos e orientando o trabalho dos professores (PERRENOUD, 2004, p.14).

Se os postulados de Perrenoud (2004) contribuiriam para enrijecer a percepção sobre a dinâmica cíclica plurianual da DEDS e da EDS, por intermédio de Hernández e Ventura (1998, p.28) busca-se, neste texto, fundamentar a importância da estrutura de um determinado percurso de formação e ritmo de assimilação de conhecimentos pelos sujeitos envolvidos.

Para Hernández e Ventura (idem), o ponto de partida nesse processo seria a necessidade de mudanças, aonde a inovação viria a partir de reflexões e discussões pedagógicas, originadas nas necessidades reais, vivenciadas em suas práticas. Ou seja, tais autores sugerem um fluxo de procedimentos pelo qual é constituído um percurso - de formação e ritmo de assimilação de conhecimentos pelos sujeitos envolvidos - a ser seguido a partir da necessidade real do cotidiano.

Ainda com base em Hernández e Ventura (idem), sendo a necessidade real do cotidiano chancelada pelos sujeitos envolvidos, segue-se a revisão dos fundamentos, a aproximação ao Campo do Currículo, desenvolvimento dos projetos, Projeto Curricular Institucional e aprofundamento ou adequação, se assim for necessário.

Nesse sentido, e em uma compreensão mais ampla dessa questão, caberia observar também uma suposta mudança paradigmática, sobretudo pelo fato de essa proposta estar sujeita a contemplar uma necessidade intrínseca do trabalho conjunto e participativo dos envolvidos no processo: alunos, professores, diretores, coordenadores pedagógicos, dentre outros profissionais da educação de modo geral - inclusive a própria sociedade -, mormente na etapa de planejamento e desenvolvimento de projetos curriculares institucionais. 
Na intenção de sintetizar a possível convergência, entre os propósitos da DEDS e da EDS com os postulados de Perrenoud (2004, p.14), bem como com os de Hernández e Ventura (1998, p.28), é oferecido o elemento pictórico da Figura 1, a seguir:

Figura 1: A DEDS e a EDS sob a perspectiva curricular nos ciclos plurianuais de aprendizagem e o percurso de formação ao longo dos anos (elaboração nossa, a partir de Perrenoud, 2004, p.14, e Hernández e Ventura, 1998, p.28)

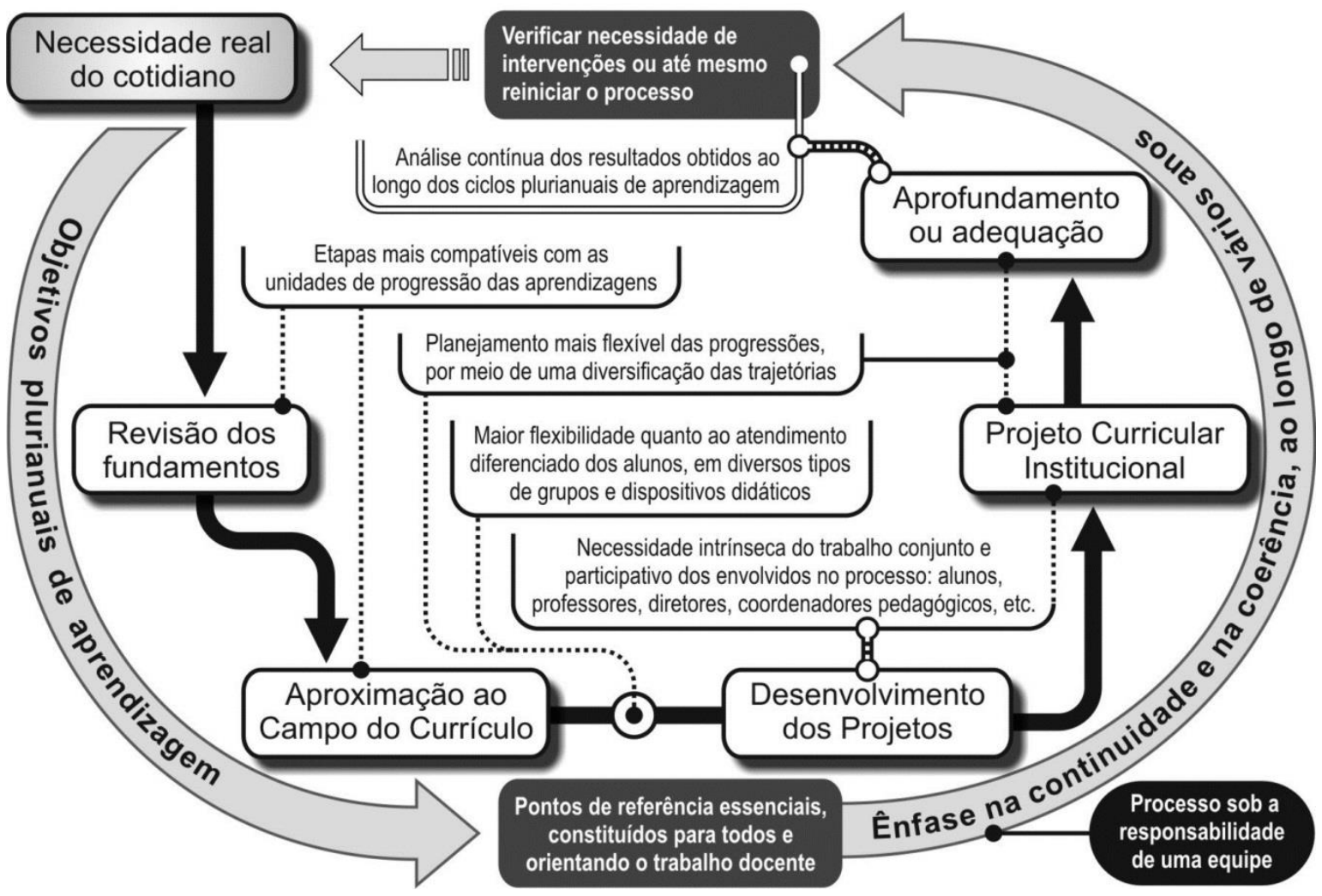

Por meio da Figura 1 é possível considerar um suposto e coerente percurso que a DEDS e a EDS deveriam percorrer desde janeiro de 2005, especificamente no âmbito das políticas públicas educacionais do Governo do Estado de São Paulo. Isso, é claro, se houvesse a necessidade real do cotidiano pelos sujeitos, em questão, "convidados" pela ONU/UNESCO a participarem do programa EDS proposto pela DEDS.

\section{A EDS no currículo da rede pública de ensino no estado de São Paulo}

Segundo o documento final do esquema internacional de implementação da Década da Educação das Nações Unidas para um Desenvolvimento Sustentável, 2005-2014 (UNESCO, 2005), bem como para a efetiva adoção da EDS, foi reservada uma atenção especial às Tecnologias de Informação e de Comunicação (TIC). Afirmou-se que elas seriam ponto vital para o êxito do programa, pois representariam uma maneira de administrar a tarefa: um meio 
para unir parceiros distantes, para armazenar dados, para compartilhar informações e notícias tão rapidamente quanto possível (UNESCO, 2005, p.80).

As TIC, portanto, deveria se estabelecer como plataforma de um processo de colaboração entre partes interessadas, pela qual haveria uma natural convergência entre a importância das TIC e os propósitos de promoção e projeção estabelecidos pelo documento de implementação da DEDS e EDS, mormente quando a UNESCO (2005, p.74) assevera que:

Para se colocar em prática a EDS é preciso que as respectivas atividades de promoção e projeção sejam generalizadas e que se tenha uma mídia responsável, comprometida em encorajar cidadãos e se manter informados e ativos. A mobilização ocorrerá em todos os níveis, envolvendo todos os atores. Os governos e a sociedade civil deveriam manter um diálogo permanente, no qual as questões sejam divulgadas e agendas comuns planejadas por intermédio de amplo debate e de aprendizagem mútua. (UNESCO, 2005, p.74).

Além de reconhecer que a implementação da DEDS e da EDS é um processo essencialmente democrático e colaborativo entre todas as partes interessadas, outros princípios relativos à implementação do programa são fornecidos pelo documento da UNESCO (2005, p.117-120), cujas operacionalidades poderiam ser sobremaneira potencializadas por meio das TICs (com ênfase para a internet). Sobretudo ao considerar que, dentre os itens do checklist relativo à implementação da EDS, consta o procedimento de examinar e adaptar currículos escolares e extracurriculares para a inclusão das abordagens para favorecer a essência de uma educação para o desenvolvimento sustentável. (p.119).

Por tudo isso, seria de se esperar uma extensa gama de resultados em sites de busca na web quanto aos aspectos curriculares vinculados à DEDS e à EDS, no âmbito da educação pública sob os cuidados do governo paulista, principalmente nos anos que compreenderiam o momento decisivo em relação ao final de tal Década, em 2014. Eis, portanto, a essência da pesquisa elaborada neste estudo: averiguar, pela perspectiva curricular, esse cenário na realidade da rede pública administrada pela Secretaria da Educação do Estado de São Paulo.

Para promover um referencial - na forma de breve diagnóstico - por meio de mapeamento prospectivo sobre a difusão relativa aos aspectos curriculares da EDS na rede pública do estado de São Paulo, não há como pretender esboçar conclusões definitivas e nem imputar juízo de valores a respectiva instância organizacional pública estudada.

Os critérios adotados consistiram na utilização das expressões exatas "década da educação para o desenvolvimento sustentável"; e "educação para o desenvolvimento sustentável", as quais se fizeram como descritores em domínios específicos que restringisse a 
busca ao universo pretendido. Para melhor entendimento, as pesquisas foram seccionadas em 5 abordagens, cujas delimitações (e ou procedimentos) definiram as respectivas abrangências:

1. Na primeira abordagem, buscou-se averiguar o quanto a DEDS foi assimilada pela Secretaria da Educação do Estado de São Paulo.

2. Na segunda, como a DEDS estaria inserida na educação pública de todo o Estado de São Paulo - bem como da administração direta e indireta dos governos municipais e estadual.

3. Na terceira, buscou-se averiguar o quanto a EDS foi assimilada pela Secretaria da Educação do Estado de São Paulo.

4. Na quarta, o quanto a Educação Ambiental (EA) estaria inserida na educação pública sob a responsabilidade da Secretaria da Educação do Estado de São Paulo.

5. Na quinta, a análise centrou-se nos currículos adotados pela Secretaria da Educação do Governo de São Paulo à sua rede pública de ensino, de modo a verificar eventuais menções ou conteúdos relacionados tanto à DEDS como, sobretudo, à EDS.

A razão de optar pelo padrão exato de busca justifica-se pelo seguinte exemplo: caso fosse adotada a expressão aberta, educação + desenvolvimento + sustentável, em detrimento da exata, não refletiria se a DEDS e/ou a EDS foi de fato incorporada às politicas educacionais públicas no pelo governo paulista, podendo representar apenas uma alusão à educação e ao desenvolvimento sustentável, algo abstrato e sem conexão contundente aos propósitos instituídos pelo Plano Internacional de Implementação da DEDS e da EDS.

Assim, após os esclarecimentos preliminares, seguem os resultados obtidos:

(1) A DEDS na Secretaria da Educação do Estado de São Paulo.

PESQUISA 1. Descritor exato: "década da educação para o desenvolvimento sustentável"

\begin{tabular}{|c|c|}
\hline Domínio específico & Resultados em 28/09/2014 \\
\hline Extensão: educacao.sp.gov.br & 01 (um) \\
\hline
\end{tabular}

O único resultado obtido na busca refere-se a um link para baixar documento intitulado Orientações para o Planejamento Escolar 2014 (SÃO PAULO, 2014), no qual, a DEDS é citada uma única vez. Quando, entre as ações elencadas, que seriam desencadeadas pela IV Conferência Infanto-juvenil pelo Meio Ambiente (CNIJMA), uma delas seria contribuir para a Década da Educação para o Desenvolvimento Sustentável e para a consecução das Metas do Milênio, ambas as iniciativas da ONU no escopo da Educação Ambiental para Sociedades Sustentáveis. Assim, fortalecer-se-ia a participação da juventude na implementação da Política Nacional de Educação Ambiental (grifo nosso), incentivando-a a contribuir com a solução dos problemas socioambientais (p.109). Conforme se observa, a DEDS foi praticamente colocada em segundo plano em razão de predominar a perspectiva da EA. 
(2) A DEDS na educação pública de todo o Estado de São Paulo - bem como em toda a administração direta e indireta do governo estadual e dos governos municipais.

PESQUISA 2. Descritor exato: "década da educação para o desenvolvimento sustentável"

\begin{tabular}{|l|c|}
\hline Domínio específico & Resultados em 28/09/2014 \\
\hline Extensão: sp.gov.br & 17 (dezessete) \\
\hline
\end{tabular}

Nesta pesquisa, o site de busca (Google) informava que para mostrar os resultados mais relevantes, foram omitidas as entradas bastante semelhantes aos 17 resultados já exibidos.

A razão de proceder a uma busca ampla por um domínio que compreenderia, além da Secretaria Estadual da Educação, todos os entes públicos do estado de São Paulo - tanto da administração pública direta como indireta, nos governos estadual ou municipais, se deu pelo resultado da Pesquisa 1, na qual foi constatada apenas uma entrada referente à DEDS.

Contudo, mesmo esta Pesquisa 2 proporcionando uma amplitude supostamente capaz de cobrir todo o arcabouço da administração pública no território paulista, o resultado de apenas 17 entradas poderia ser considerado pífio. Para verificar se haveria alguma distorção por conta da exatidão do descritor utilizado, procedeu-se a uma nova pesquisa complementar a esta Pesquisa 2, adotando um descritor composto: "década" + "educação para o desenvolvimento sustentável”, e o resultado se repetiu: apenas 17 entradas.

Há certa insignificância quantitativa se considerarmos que o estado de São Paulo se trata de uma Unidade Federativa do Brasil economicamente forte, detentora de extensa rede pública de ensino estadual e municipal, com 645 municípios. Além da quantidade pífia, da análise de cada resultado, verificou-se que a DEDS foi lançada em materiais sem qualquer preocupação em se aprofundar ou em se alinhar aos propósitos tanto da DEDS como da EDS.

(3) A EDS na Secretaria da Educação do Estado de São Paulo.

PESQUISA 3. Descritor exato: “educação para o desenvolvimento sustentável”

\begin{tabular}{|c|c|}
\hline Domínio específico & Resultados em 28/09/2014 \\
\hline Extensão: educacao.sp.gov.br & Nihil (apenas o mesma entrada da \\
& Pesquisa 1) \\
\hline
\end{tabular}

PESQUISA 4. Descritor exato: “educação para o desenvolvimento sustentável”

\begin{tabular}{|c|c|}
\hline Domínio específico & Resultados em 28/09/2014 \\
\hline Extensão: edunet.sp.gov.br & 03 (três) \\
\hline
\end{tabular}

Nesta pesquisa considerou-se também o domínio com extensão "edunet", que é uma plataforma utilizada pela Secretaria de Educação do Estado de São Paulo (SEE), pela qual se 
integra recursos instrucionais, de capacitação profissional e demais conteúdos a serem difundidos, destinada tanto à sua rede de ensino como à sociedade em geral.

Da análise dos resultados, apurou-se em linhas gerais que se tratavam de expedientes informativos relativos à IV CNIJMA, postados pelas Diretorias de Ensino (D.E.) vinculadas à Secretaria Estadual de Educação: D.E. Penápolis, D.E. Araçatuba (ambas do interior do estado) e D.E. Região Centro Oeste de São Paulo, no bairro de Sumaré, na capital. Pelo teor de tais comunicações, constatou-se apenas a menção de que a CNIJMA estaria, em tese, contribuindo para a Década da Educação para o Desenvolvimento Sustentável (DEDS) e para a consecução das Metas do Milênio. Ou seja, a EDS sequer foi levada em consideração.

(4) A Educação Ambiental (EA) na Secretaria da Educação do Estado de São Paulo.

PESQUISA 5. Descritor exato: "educação ambiental"

\begin{tabular}{|c|c|}
\hline Domínio específico & Resultados em 28/09/2014 \\
\hline Extensão: educacao.sp.gov.br & 19 (aproximadamente) \\
\hline
\end{tabular}

PESQUISA 6. Descritor exato: “educação ambiental”

\begin{tabular}{|c|c|}
\hline Domínio específico & Resultados em 28/09/2014 \\
\hline Extensão: edunet.sp.gov.br & 41 (aproximadamente) \\
\hline
\end{tabular}

Tanto na Pesquisa 5 como na 6 , o site de busca (Google) informava que para mostrar os resultados mais relevantes, foram omitidas as entradas bastante semelhantes aos 19 e 41 resultados já exibidos, respectivamente. Os resultados obtidos sugerem que, apesar de uma maior quantidade de entradas referentes à EA sobre a EDS, ainda assim, devido a não significativa quantidade de resultados, não seria possível afirmar que o tema sobre o desenvolvimento sustentável estaria consolidado na política educacional do governo paulista.

(5) A DEDS e a EDS nos currículos adotados pela Secretaria da Educação do Governo de São Paulo na sua rede pública de ensino.

Conforme verificado pelos resultados obtidos nas pesquisas anteriores - principalmente quanto às abordagens de 1 a 3 -, percebe-se que, tanto a DEDS como a EDS, não foram evidenciadas, de forma contundente, pelas políticas educacionais do governo paulista durante o percurso decenal estabelecido pela ONU para a DEDS. Sequer nesse momento crucial, onde o prazo definido pela ONU se expira em dezembro deste ano de 2014.

Em que pese até uma possível postura vilipendiosa por parte do governo estadual paulista nesse sentido, o fato de as TIC, aliadas à internet, serem fundamentais para a difusão da DEDS 
e da EDS, e que nos procedimentos de buscas relacionadas a tais propostas da ONU na rede mundial de computadores, a quantidade de resultados, se não foram nulos, ficaram entre pífios e insignificantes, só restou recorrer em última instância a uma análise qualitativa neste estudo: se ao menos os currículos da rede estadual ofereciam elementos suficientes para que os pressupostos da EDS fossem levados a efeito.

A base curricular oficial adotada pela rede pública de ensino do governo estadual paulista, tanto Fundamental como Médio, foi definida em 2011, cuja estrutura compreendeu quatro áreas: (1) Ciências da Natureza; (2) Ciências Humanas; (3) Linguagem e Códigos; e (4) Matemática. Desde então não houve qualquer revisão ou reedição. Ou seja, pelo próprio site da Secretaria da Educação paulista, tais currículos podem ser baixados ${ }^{9}$, constatando de fato a validade dos mesmos neste último biênio da DEDS, estando eles ainda em vigência.

A partir dos currículos oficiais vigentes, desenvolveu-se uma análise de seus conteúdos de modo a verificar a que ponto os mesmos estariam alinhados em relação aos propósitos da DEDS, sobretudo quanto a prevalecê-los na dinâmica curricular da rede pública escolar do governo paulista em relação à EDS, na forma de uma necessidade real do cotidiano.

Nesse procedimento foi ratificado que não houve qualquer menção à DEDS ou à EDS. Ademais, constatou-se que apenas os currículos das áreas das Ciências da Natureza (e suas tecnologias) e das Ciências Humanas (e suas tecnologias) ofereciam alguma pertinência aos objetivos pretendidos por esta pesquisa. $O$ primeiro passo da análise consistiu no levantamento, em cada um desses currículos, do número de citações de palavras-chave em suposta relação aos propósitos da EDS, cujos resultados são demonstrados pela Tabela 1.

Tabela 1: Número de citações de palavras-chave supostamente relacionadas à EDS, nos currículos oficiais das Ciências da Natureza $(\mathrm{CN})$ e das Ciências Humanas $(\mathrm{CH})$ da rede pública de ensino do estado de São Paulo (Fontes: SÃO PAULO, 2011a e 2011b)

\begin{tabular}{|l|c|c|}
\hline PALA VRAS-CHA VE & CN & CH \\
\hline Agenda 21 & 0 & 0 \\
\hline Ambiental & 16 & 17 \\
\hline $\begin{array}{l}\text { Consciência/Consciente/Conscientizaç } \\
\text { ão }\end{array}$ & 12 & 13 \\
\hline Década da... & 0 & 0 \\
\hline Desenvolvimento sustentável (DS) & 3 & 3 \\
\hline Ecologia & 0 & 0 \\
\hline
\end{tabular}

\begin{tabular}{|l|c|c|}
\hline $\begin{array}{l}\text { PALAVRAS- } \\
\text { CHAVE }\end{array}$ & CN & CH \\
\hline $\begin{array}{l}\text { Impacto(s) } \\
\text { ambiental(is) }\end{array}$ & 9 & 2 \\
\hline Meio Ambiente & 9 & 3 \\
\hline $\begin{array}{l}\text { ONU/Organização das } \\
\text { Nações Unidas }\end{array}$ & 0 & 4 \\
\hline Poluição & 22 & 2 \\
\hline Preservar/Preservação & 12 & 17 \\
\hline
\end{tabular}

9 Disponível em: 〈http://www.educacao.sp.gov.br/portal/projetos/curriculo-do-estado-de-sao-paulo>. Acesso em: set.2014. 


\begin{tabular}{|c|c|c|c|c|c|}
\hline Ecológico(a) & 5 & 0 & Recursos naturais & 0 & 14 \\
\hline Educação Ambiental & 1 & 0 & Sustentabilidade & 2 & 0 \\
\hline $\begin{array}{l}\text { Educação para o desenvolvimento } \\
\text { Sustentável }\end{array}$ & 0 & 0 & $\begin{array}{l}\text { Sustentável: } \\
\text { desconsideradas as } \\
\text { três citações no DS. }\end{array}$ & 1 & 1 \\
\hline Futuro & 3 & 4 & UNESCO & 0 & 0 \\
\hline
\end{tabular}

Legenda: CN - Ciências da Natureza (152 páginas); CH - Ciências Humanas (152 páginas)

Logo na prospecção da primeira palavra-chave seria possível perceber o quanto os conteúdos de tais currículos estariam distantes dos propósitos da EDS; pois, constatar que em nenhum momento a Agenda 21 foi levada em consideração no contexto curricular, já seria motivo suficiente para fundamentar tal inferência. Pela Tabela 1, além da omissão da DEDS e da EDS, se constata ainda que outros termos relevantes, devidamente destacados, deixaram de ser citados ou foram mencionados em poucas ocasiões, tais como: ecologia, educação ambiental, ONU e recursos naturais (omissões justamente nas CN!) e sustentabilidade.

Quanto à palavra-chave desenvolvimento sustentável, apesar de a mesma ter sido mencionada três vezes em cada um dos currículos analisados $(\mathrm{CN}$ e $\mathrm{CH})$, e considerando se tratar de uma expressão fundamental aos propósitos deste estudo, caberia uma discussão mais aprofundada em relação ao contexto curricular em que tal termo foi lançado.

a) O desenvolvimento sustentável no contexto do currículo das CN (SÃO PAULO, 2011a):

- Currículo de Química, tópico Química para o Ensino Médio, p. 126-127: [...] os conceitos químicos envolvidos em processos de produção de energia devem ser compreendidos de forma prática e também em relação aos contextos ambientais políticos e econômicos, considerando a perspectiva do desenvolvimento sustentável.

- Currículo de Química, conteúdos para a $3^{\text {a }}$ série do Ensino Médio, p. 150: O que o ser humano introduz na atmosfera, hidrosfera e biosfera: Poluição, perturbações da biosfera, ciclos biogeoquímicos e desenvolvimento sustentável: Impactos ambientais na óptica do desenvolvimento sustentável.

b) O desenvolvimento sustentável no contexto do currículo das CH (SÃO PAULO, 2011b):

- Currículo de Geografia, conteúdos para $7^{\circ}$ série $/ 8^{\circ}$ ano do Ensino Fundamental, p. 93: A crise ambiental: [...] Do Clube de Roma ao desenvolvimento sustentável.

- Currículo de Geografia, habilidades para $1^{\mathrm{a}}$ série do Ensino Médio, $4^{\circ}$ bimestre, p. 104: Propor formas de atuação para conservação do ambiente e desenvolvimento sustentável.

- Currículo de Geografia, habilidades para $2^{a}$ série do Ensino Médio, $4^{\circ}$ bimestre, p. 108: Propor formas de atuação para conservação dos diferentes domínios florestados e defender políticas que considerem formas de desenvolvimento sustentável. 


\section{Considerações finais}

Segundo Layrargues (2012), poucos temas teriam o privilégio de receber o destaque e a atenção pública que a ONU dedicou à DEDS e à EDS. Tais propostas teriam constituído o mais importante programa que surgiu entra a Rio 92 e a Rio+20. No entanto, o autor já alertava, em 2012, que a década passava praticamente despercebida e sem grandes efeitos para influenciar mudanças na educação voltada aos aspectos preservacionistas, sobretudo quanto a promover uma consciência sobre o que seria um desenvolvimento sustentável.

No caso específico do governo paulista, se por meio dos resultados deste estudo não há como dizer, de forma contundente, que o programa da ONU foi vilipendiado ou tergiversado pelas suas políticas educacionais, há elementos suficientes para inferir que a identificação, bem como o comprometimento por parte do governo de São Paulo, de levar a efeito os propósitos da DEDS e da EDS, teria ficado muito aquém das expectativas; pelo menos no que diz respeito a elas não terem se mostrado como uma necessidade real do cotidiano nesses dez anos, tampouco para desencadear seus ciclos plurianuais de aprendizagem e conscientização.

\section{Referências}

ARID, F. M. (2003). Doutrina e desafios ambientais. São Paulo: Ed. da UNESP.

BASTOS, A. M. (2007). Gavião Peixoto: um século de sua história e as dimensões de sustentabilidade no seu desenvolvimento. 2007. 620f. Dissertação (Mestrado em Desenvolvimento Regional e Meio Ambiente) - Uniara - Centro Universitário de Araraquara, Araraquara.

BASTOS, A. M.; SOUZA, C.B.G. (2013). A educação e a sustentabilidade: o desafio de um paradigma e a década da educação para o desenvolvimento sustentável da UNESCO (20052014). Revista Ibero-Americana de Estudos em Educação. v. 8, n. 1. p. 208-240.

BRASIL (1995). Câmara dos Deputados. CNUMAD - Conferência das Nações Unidas sobre o meio ambiente e desenvolvimento (Rio de Janeiro: 1992): de acordo com a Resolução $n^{\circ}$ 44/228 da Assembleia Geral da ONU, de 22-12-89, estabelece uma abordagem equilibrada e integrada das questões relativas a meio ambiente e desenvolvimento: a Agenda 21. Brasília: Câmara dos Deputados, Coordenação de Publicações, 1995. 472p. (Série Ação Parlamentar, n.56).

MMA (n.d.[a]). Ministério do Meio Ambiente. Agenda 21. Brasília: Portal do MMA. Disponível em: <http://www.mma.gov.br/component/k2/item/569?Itemid=670>. Acesso: jul. 2012.

MMA (n.d.[b]). Ministério do Meio Ambiente. Agenda 21 global. Brasília: Portal do MMA. Disponível em: <http://www.mma.gov.br/responsabilidade-socioambiental/agenda21/agenda-21-global>. Acesso em: jul. 2012.

BRUNDTLAND, G. H. (2012). Há abuso no uso de sustentabilidade, diz criadora do termo. Folha de S.Paulo, 22.março.2012, Caderno Cotidiano-Ciência, p.C17. Entrevista a Cláudio Ângelo. Disponível em: <http://www1.folha.uol.com.br/ambiente/1065497-ha-abuso-nouso-de-sustentabilidade-diz-criadora-do-termo.shtml>. Acesso em: julho. 2012. 
COSTANZA, R.; DALY, H. E.; BARTHOLOMEW, J. A. (1991). Goals, agenda and policy recommendations for ecological economics. In: COSTANZA, R. (ed.) (1991). Ecological economics: the science and management of sustainability. Edited by Robert Costanza. New York, USA, Columbia University Press, p. 1-20.

GONZÁLEZ, F. C. E.; GINDRI, B. S. (2004). A função da escola e a realidade socioambiental circundante. Campo Grande: Rede Pantanal de Educação Ambiental. Disponível em: <http://www.redeaguape.org.br/artigo.php?id=42>. Acesso: 12 jul. 2012.

HERNÁNDEZ, F.; VENTURA, M. (1998). A organização do currículo por projetos de trabalho: o conhecimento é um caleidoscópio. 5 ed. Porto Alegre-RS: Artmed.

IBRAM-DF (2001). Instituto do meio Ambiente e dos recursos hídricos do Distrito Federal. Educação ambiental no Brasil. Brasília-DF: IBRAM. Disponível em: <http://www.ibram.df.gov.br/005/00502001.asp?ttCD_CHAVE=12943>. Acesso: 12 jul. 2012.

LAYRARGUES, P. P. (2012). Educação Ambiental no Brasil: o que mudou nos vinte anos da Rio 92 à Rio+20. ComCiência - Revista eletrônica de jornalismo científico. Disponível em: <http://www.comciencia.br/comciencia/?section=8\&edicao=75\&id=938>. Acesso: set.2013.

LEMES, S. S. (2013). O currículo para a escola democratizada: das pistas históricas às perspectivas necessárias. In: COLVARA, L. D. Caderno de Formação: formação de professor: Gestão Escolar, v.2, Bloco 03, D28: Gestão Curricular. São Paulo: Cultura Acadêmica: UNESP - Pró-Reitoria de Graduação: Univesp, p.170-181.

MEDINA, N. M (1997). Breve histórico da educação ambiental. In: PÁDUA, S.M.; \& TABANEZ, M.F. (Org.). Educação ambiental: caminhos trilhados no Brasil. Brasília: Ipê, p.265-269.

MELLO, L. F.; OJIMA, R. (2004). Além das certezas e incertezas: desafios teóricos para o mito da explosão populacional e os acordos internacionais. In: XIV ENCONTRO NACIONAL DE ESTUDOS POPULACIONAIS, 20 a 24 set., 2004, Caxambu. Anais...Caxambu: ABEP, 2004.

ONU BRASIL (1972). Organizações das Nações Unidas. Escritório de representação fixa no Brasil. Declaração da Conferência das Nações Unidas sobre o Meio Ambiente Humano - 1972 ("Declaração de Estocolmo"). Estocolmo, Suécia, 1972. Disponível em: <http://www.onu.org.br/rio20/img/2012/01/estocolmo1972.pdf > . Acesso em: jul. 2012.

(n.d.). Organizações das Nações Unidas. Escritório de representação fixa no Brasil. A ONU e o meio ambiente. Brasília, (n.d.). Disponível em: <http://www.onu.org.br/a-onuem-acao/a-onu-e-o-meio-ambiente/>. Acesso em: jul.2012.

PERRENOUD, P. (2004). Os ciclos de aprendizagem: um caminho para combater o fracasso escolar. Porto Alegre-RS: Artmed, 2004.

SACHS, I. (1993). Estratégias de transição para o século XXI: desenvolvimento e meio ambiente. São Paulo: Studio Nobel: FUNDAP.

SÃO PAULO (2014). Secretaria da Educação. Coordenadoria de Gestão da Educação Básica. Orientações para o planejamento escolar 2014. São Paulo. Disponível em: <http://www.educacao.sp.gov.br/a2sitebox/arquivos/documentos/669.pdf>. Acesso em: ago.2014. 
(2011a). Secretaria da Educação. Currículo do Estado de São Paulo: Ciências da Natureza e suas tecnologias / Secretaria da Educação; coordenação geral, Maria Inês Fini; coordenação de área, Luis Carlos de Menezes. - 1. ed. atual. - São Paulo: SE, 2011.152 p. Disponível em: <http://www.educacao.sp.gov.br/portal/projetos/curriculo-do-estado-desao-paulo>. Acesso: set.2014.

(2011b). Secretaria da Educação. Currículo do Estado de São Paulo: Ciências

Humanas e suas tecnologias / Secretaria da Educação; coordenação geral, Maria Inês Fini; coordenação de área, Paulo Miceli . - 1. ed. atual. - São Paulo : SE, 2011. 152 p. Disponível em: <http://www.educacao.sp.gov.br/portal/projetos/curriculo-do-estado-de-sao-paulo>. Acesso: set.2014.

SOUZA, A. L. L. (1994). Meio ambiente e desenvolvimento sustentável: uma reflexão crítica. São Paulo: SEBRAE.

THE CLUB OF ROME. Winterthur, Cantão Zurique, Suíça (1972). Limits of Growth. Disponível em: <http://www.clubofrome.org/?p=326>. Acesso em: set. 2014.

. Winterthur, Cantão Zurique, Suíça (n.d.). About us and History. Disponível em: <http://www.clubofrome.org>. Acesso em: jul. 2012.

. Capítulo Argentino (n.d.). Quem somos e histórico. Disponível em: <http://www.clubderoma.org.ar/pt/quem-somos/conselho-diretivo/12-capituloargentino.html>. Acesso em: jul. 2012.

UNEP (1972). United Nations Environment Programme (PNUMA. Programa das Nações Unidas para o Meio Ambiente). Declaration of the United Nations Conference on the Human Environment. Stockholm, Sweden, 1972. Disponível em: http://www.unep.org/Documents.Multilingual/Default.asp?DocumentID=97\&ArticleID=1 503\&l=en >. Acesso em: jul. 2012.

UNESCO (2005). Organização das Nações Unidas para a Educação, a Ciência e a Cultura. Década da educação das Nações Unidas para um desenvolvimento sustentável, 2005 2014: documento final do esquema internacional de implementação. Brasília: UNESCO, 2005. Disponível em: 〈http://unesdoc.unesco.org/images/0013/001399/139937por.pdf〉. Acesso em: 12 jul. 2012.

UNITED NATIONS (1987). CMMAD - Comissão Mundial sobre Meio Ambiente e Desenvolvimento. Nosso futuro comum. Documentos da ONU: relatório transmitido à Assembleia Geral, anexo ao documento A/42/427 - Desenvolvimento e Cooperação Internacional: Ambiente. Noruega: Oslo, 1987. Disponível em: <http://www.undocuments. net/wced-ocf.htm>. Acesso: 12 jul. 2012.

(2002). Resolução 57/254, Sessão 57 . United Nations decade of education for sustenaible development Disponível em: 〈http://www.un-documents.net/a57r254.htm>. Acesso: julho/2012. 